\title{
Growth Advantage and Enhanced Toxicity of Escherichia coli Adherent to Tissue Culture Cells due to Restricted Diffusion of Products Secreted by the Cells
}

\author{
Dina Zafriri," Y. Oron," Barry I. Eisenstein," and Itzhak Ofek* \\ Departments of *Human Microbiology, ${ }^{\ddagger}$ Physiology and Pharmacology, Sackler School of Medicine, Tel-Aviv University, Tel-Aviv 69978, \\ Israel; and Microbiology and Medicine, University of Texas Health Science Center at San Antonio, San Antonio, Texas 78284
}

\begin{abstract}
This study was undertaken to examine whether Escherichia coli adherent to tissue cells gain advantages over nonadherent bacteria due to their proximity to the cells. We used tissue culture cells and isogenic derivatives of a proline auxotrophic strain of $E$. coli that were fimbriated $\left(\mathrm{Fim}^{+}\right)$or nonfimbriated $\left(\mathrm{Fim}^{-}\right)$, and were heat-labile enterotoxin producing $\left(\mathrm{Tox}^{+}\right)$or toxin nonproducing $\left(\mathrm{Tox}^{-}\right)$. We found that the Fim ${ }^{+}$bacteria, which were capable of adhering to tissue culture cells, initiated growth much sooner than did nonadherent $\mathrm{Fim}^{-}$bacteria; the adherent bacteria used tissue cell-derived proline, which was available at high concentrations only in the zone of bacterial adherence. Likewise, cyclic AMP secreted by adherent $\left(\mathrm{Fim}^{+}\right)$bacteria was maintained at high concentration on the tissue cell surfaces. As few as $2 \times 10^{5}$ adherent $\mathrm{Fim}^{+} \mathrm{Tox}^{+}$bacteria exert toxic activity upon Y1 adrenal cells, whereas toxin secreted in the medium by $6 \times 10^{6} \mathrm{Fim}^{-}$ $\mathrm{Tox}^{+}$bacteria was undetectable. The results suggest that the growth advantage and enhanced toxicity of adherent $E$. coli is due to restricted diffusion of products secreted by the tissue culture and bacterial cells, respectively.
\end{abstract}

\section{Introduction}

Bacterial adherence to mucosal cells is an important step in the infectious process for at least three reasons $(1,2)$. First, and probably the most important, is that bacterial attachment protects the bacteria from being swept away by the normal cleansing mechanisms operating on mucosal surfaces (e.g., urinary flow, peristalsis). Second, penetration of the mucosal barrier must somehow proceed by the adherence of the invading bacteria onto the cell surface. Finally, it has been postulated, without direct evidence, that secreted toxic products may reach their cell target more efficiently when secreted by adherent bacteria than when secreted by nonadherent bacteria (3).

Despite reasonable evidence, however, that bacterial adherence to mucosal tissues plays a major role in the infectious process, little information is available concerning the molecular mechanisms that confer an advantage to adherent, as compared with nonadherent, bacteria in their survival, proliferation, and

Address reprint requests to Dr. Eisenstein, whose present address is Department of Microbiology and Immunology, University of Michigan Medical School, Ann Arbor, MI 48109.

Received for publication 28 April 1986 and in revised form 26 September 1986.

J. Clin. Invest.

(c) The American Society for Clinical Investigation, Inc. 0021-9738/87/04/1210/07 $\$ 1.00$

Volume 79, April 1987, 1210-1216 ability to cause tissue damage. In particular, little is presently known regarding the effect of bacterial adherence to tissues on either the ability of the growing bacteria to use nutrients liberated by the target tissue or the distribution of secreted bacterial products in the medium relative to those in the tissue-media interface. Consequently, this study was undertaken to examine these two secretion activities in a system, using tissue culture cells and various isogenic mutants of Escherichia coli. We found that there was both a growth advantage and an enhanced effect of heatlabile enterotoxin (LT) ${ }^{1}$ in $E$. coli capable of adhering to tissue cells, possibly due to a high concentration, in crypts formed by the ruffle structures of the animal cells, of the respective secreted products.

\section{Methods}

Bacteria. The K-12 proline auxotrophic $E$. coli strains used in this study have been described elsewhere $(4,5)$. Briefly, they are the fimbriated $\left(\mathrm{Fim}^{+}\right)$strain CSH50, harboring either plasmid pBR322 or the pBR322derived, LT $^{+}$plasmid, $\mathrm{p} \Delta \mathbf{2 9 9}$ (kindly supplied by Dr. P. C. Tai of Harvard University), its nonfimbriated $\left(\mathrm{Fim}^{-}\right.$) derivative, strain VL584, and a $\mathrm{Fim}^{+} \mathrm{Cya}^{-}$derivative strain VL391, which does not produce cyclic AMP (cAMP). Two additional proline auxotrophic strains of $E$. coli (AB 2659 and Met F3455) were also included (kindly supplied by Dr. E. Ron from Department of Microbiology, Tel-Aviv University). Bacteria were grown in trypticase soy broth at $37^{\circ} \mathrm{C}$ for $48 \mathrm{~h}$.

Tissue culture cell line. The human intestinal epithelial cell-line CCL6 (ATCC collection) was used. In all tests, wells of $3 \mathrm{~cm}$ in diameter in tissue culture plates, were seeded with $2 \times 10^{5}$ cells/well in $3 \mathrm{ml}$ of Hanks' minimal essential medium (MEM) supplemented with $1.0 \mathrm{mM}$ L-glutamine, $40 \mathrm{U} / \mathrm{ml}$ penicillin, $40 \mu \mathrm{g} / \mathrm{ml}$ streptomycin, and $10 \%$ fetal calf serum (FCS) and incubated for $72 \mathrm{~h}$ at $37^{\circ} \mathrm{C}$ in a humidified atmosphere of $5 \% \mathrm{CO}_{2}$ in air, to obtain a confluent monolayer of cells. Y1 mouse adrenal cortex tumor cells (ATCC collection) were grown in 1.5-diameter wells in $1 \mathrm{ml}$ Earle's MEM supplemented with 10\% FCS to obtain confluent monolayers of $\sim 10^{5}$ cells/cell. All tissue cell monolayers were washed twice with phosphate-buffered saline (PBS; $0.02 \mathrm{M}$ phosphate and $0.15 \mathrm{M} \mathrm{NaCl}$; $\mathrm{pH} \mathrm{7.4)} \mathrm{before} \mathrm{assay.}$

Tissue culture assay system. Stationary phase bacteria were diluted in fresh trypticase soy broth medium, grown to a late log phase, centrifuged, and washed twice with PBS. Fim ${ }^{+}$bacteria were suspended in this buffer to obtain a cell density reading of $0.5 \mathrm{OD}_{540}\left(\sim 5 \times 10^{8}\right.$ bacteria/ $\mathrm{ml}) .1 \mathrm{ml}$ of the suspension was added to each well containing washed tissue cells and after $30 \mathrm{~min}$, the supernatant was decanted and the monolayers were washed five times with PBS. $3 \mathrm{ml}$ of Hanks' MEM (without antibiotics) were then added to each well.

In separate experiments to test the effects of nonadherence, Fim ${ }^{-}$ bacteria were suspended in Hanks' MEM and diluted in the same medium to $\sim 10^{7}$ bacteria/ml; $3 \mathrm{ml}$ of the diluted suspension were added to

1. Abbreviations used in this paper: CAMP, cyclic AMP; CFU, colonyforming units; $\mathrm{Fim}^{+}$, fimbriated; Fim $^{-}$, nonfimbriated; IBMX, isobutylmethylxanthine; ${ }^{125}$ I-TSME, ${ }^{125}$ I-iodotyrosylmethylsuccinyl ester; LT, heat-labile enterotoxin; MEM, minimal essential medium. 
washed tissue culture cell monolayers. Test agents were included in the Hanks' MEM diluent. All bacteria-tissue culture cell mixtures were incubated at $37^{\circ} \mathrm{C}$ at constant shaking for a total period of 5-6 h to determine cAMP concentrations and amount of bacterial growth.

Determination of bacterial growth. In these experiments controls wells, lacking tissue culture cells but otherwise treated the same, were included. In addition, in one set of experiments, $10 \mu \mathrm{g} / \mathrm{ml}$ proline was added to Hanks' MEM diluent. 100- $\mu$ l samples of supernatant were taken from wells containing Fim ${ }^{-}$bacteria with tissue culture cells and from wells lacking tissue culture cells at $1-\mathrm{h}$ intervals for viable counts by plating on nutrient agar and determining colony-forming units (CFU). In the case of $\mathrm{Fim}^{+}$bacteria, which, unlike the Fim ${ }^{-}$bacteria, were adherent to the tissue culture cells, the medium was decanted at $1-\mathrm{h}$ intervals and the cell monolayer was washed twice with PBS and then treated with $4 \%$ saponin with vigorous shaking to remove the tissue cells from the plastic and dissociate the adherent bacteria. The viable count was then determined in the saponin wash. Saponin had no effect on the viability of the organisms (data not shown).

In a separate set of experiments, bacterial growth was monitored spectrophotometrically at $540 \mathrm{~nm}$. In these experiments, the growth medium was either fresh Hanks' MEM supplemented with various concentrations of proline, or Hanks' MEM not supplemented with proline and preincubated for $5 \mathrm{~h}$ on tissue culture cells, designated conditioned medium. Washed stationary phase bacteria were seeded into $2 \mathrm{ml}$ of the growth media and incubated for $24 \mathrm{~h}$ at $37^{\circ} \mathrm{C}$.

CAMP determination. cAMP was determined by radioimmunoassay, essentially as described by Steiner (6) and Harper and Brooker (7).

After aspiration of the medium, tissue culture cells in each well were resuspended in cold 5\% TCA for $30 \mathrm{~min}$, sonified in a Branson 3-A sonifier for $2 \mathrm{~min}$, and the precipitate removed by centrifugation. TCA was removed from the extract by four extractions with $2 \mathrm{ml}$ water-saturated diethyl ether and the ether was removed by $5 \mathrm{~min}$ heating at $60^{\circ} \mathrm{C}$ and subsequent brief application of low vacuum. The extract was diluted to a desired concentration and was acetylated with acetic anhydride in the presence of triethylamine. A 50- $\mu$ l aliquot of the acetylated extract was incubated, with anti-cAMP antibody (dilution 1:60,000) and $\sim 10^{4}$ cpm of ${ }^{125}$ I-iodotyrosylmethylsuccinyl ester of cAMP ( ${ }^{125}$ I-TSME-cAMP) for $14-18 \mathrm{~h}$ at $4^{\circ} \mathrm{C}$. After incubation, the bound ligand was separated from the free by adsorption on activated charcoal. Values were calculated from a standard curve by a curve-fitting program supplied by a Compugamma counter (LKB Instruments, Inc., Gaithersburg, MD). Determination of CAMP in the bacteria-tissue cells supernatant was performed essentially in the same way, except that the sonication step was omitted. To ensure the validity of the results, serial dilutions were assayed, as well as internal standards.

Determination of LT activity. $0.5-\mathrm{ml}$ aliquots of various bacterial suspensions or culture supernatants were added to a confluent $Y 1$ mouse adrenal cell monolayer with and without anti-LT toxin and incubated for $30 \mathrm{~min}$ at $37^{\circ} \mathrm{C}$. The monolayers were then washed three times with PBS and incubated in $1 \mathrm{ml}$ Earle's MEM without antibiotics for $4 \mathrm{~h}$ at $37^{\circ} \mathrm{C}$. LT activity was determined as the percentage of rounded cells in several representative fields (8). The amount of adherent bacteria was determined on stained monolayer microscopically by counting the number of adherent bacteria on 100 cells and multiplying by $10^{3}$ to obtain the number of adherent bacteria per well.

Preparation of anti-cholera toxin. Pure cholera toxin (Swiss Serum and Vaccine Institute, Berne, Switzerland) was suspended in saline to a concentration of $400 \mu \mathrm{g} / \mathrm{ml}$ and mixed 1:1 with complete Freund adjuvant. Rabbits were injected intramuscularly with the mixture and bled as described previously (9). These antisera were used as anti-LT toxin given the known strong antigenic crossreactivity between the two toxins (10).

Chemicals and media. Anti-cAMP antibody was a generous gift of Dr. G. Brooker of Georgetown University. ${ }^{125}$ I-TSME-cAMP was synthesized and purified in our laboratory. Tyrosylmethylsuccinyl cAMP was the product of Sigma Chemical Co. All other chemicals and media used in these studies were of the highest quality and purity available.

\section{Results}

In preliminary studies to determine the effect of bacterial fimbriation on tissue cell adherence, wells containing tissue cell monolayers were exposed to suspensions of the Fim ${ }^{+}$and $\mathrm{Fim}^{-}$ strains of $E$. coli in PBS for $30 \mathrm{~min}$ at $4^{\circ} \mathrm{C}$ followed by washing to remove nonadherent bacteria. We found that about $1 \times 10^{7}$ CFU of $E$. coli cells adhered to the tissue cell monolayer exposed to $5 \times 10^{8} \mathrm{CFU}$ of $\mathrm{Fim}^{+} E$. coli and that this adherence was significantly ( $>90 \%$ ) blocked by $\alpha$-methyl-D-mannoside, confirming that the $\mathrm{Fim}^{+}$bacteria adhere via mannose specific adhesins (Type 1 fimbriae) to the intestinal cell monolayer (11). In contrast, $<10^{6} \mathrm{CFU}$ of Fim $^{-}$cells adhered to the tissue cell monolayer. In subsequent experiments with tissue cell monolayers, therefore, the adherent $\mathrm{Fim}^{+}$bacteria after wash contained $\sim 10^{7} \mathrm{CFU}$ per monolayer. Consequently, the subsequent biochemical assays of the $\mathrm{Fim}^{+}$bacteria were performed by adding to the bacteria-adherent monolayers sterile test medium, whereas assays of the Fim ${ }^{-}$bacteria were performed by first diluting the bacterial suspension in the test medium and then adding it to the tissue cell monolayers in equal final volumes that contained $10^{7} \mathrm{CFU}$.

Growth of bacteria on intestinal cell monolayers. The growth of $\mathrm{Fim}^{-}$and $\mathrm{Fim}^{+}$stains in MEM medium was proline dependent in wells devoid of cell monolayers (Table I). In contrast, when both bacterial strains were allowed to grow in wells containing intestinal cell monolayer in proline-free medium, there was $\sim 10$-fold increase in CFU during the 6-h growth period (Fig. 1). There was, however, a difference in the lag period between the two strains. While the Fim ${ }^{+}$organisms started to grow immediately, the nonadherent Fim $^{-}$organisms started to grow $2 \mathrm{~h}$ after their inoculation to the wells. The $\mathrm{Fim}^{+}$bacteria actually started to grow sooner in wells with tissue cells and prolinedeficient medium than they did in proline-supplemented medium without the tissue cells (Table I). Such differences were not seen for the Fim ${ }^{-}$organisms. The longer lag observed in Fim $^{-}$bacteria grown on cell monolayers alone, as compared with that in the presence of monolayers and proline, represents the period required for the proline substitute to reach critical concentrations to enable the initiation of growth in the bulk medium. It should be noted that there was a difference, under the experimental conditions, in the duration of the lag period

Table I. Dependence of the Growth of Fim ${ }^{+}$and Fim ${ }^{-}$Proline Auxotrophs of E. coli on Tissue Culture Cells and Proline

\begin{tabular}{|c|c|c|c|c|c|}
\hline \multicolumn{2}{|c|}{$\begin{array}{l}\text { Content of wells in } \\
\text { addition to MEM } \\
\text { Hanks' medium }\end{array}$} & \multicolumn{2}{|l|}{$\mathrm{Fim}^{+}$} & \multicolumn{2}{|l|}{$\mathrm{Fim}^{-}$} \\
\hline $\begin{array}{l}\text { Tissue } \\
\text { cells }\end{array}$ & $\begin{array}{l}\text { Proline } \\
(10 \mu \mathrm{g} / \mathrm{ml})\end{array}$ & $\begin{array}{l}\text { Generation } \\
\text { time* }\end{array}$ & Lag phase & $\begin{array}{l}\text { Generation } \\
\text { time }\end{array}$ & Lag phage \\
\hline & & $\min$ & $\min$ & $\min$ & $\min$ \\
\hline Absent & not added & no growth & & no growth & \\
\hline Absent & added & $42.6 \pm 7.0$ & $56.5 \pm 8.0$ & $43.7 \pm 0.7$ & $125.0 \pm 12$ \\
\hline Present & not added & $37.9 \pm 1.3$ & 2.0 & $42.3 \pm 4.0$ & $100.5 \pm 11$ \\
\hline Present & added & $42.3 \pm 1.8$ & 2.0 & $45.2 \pm 8.0$ & $41.7 \pm 2.6$ \\
\hline
\end{tabular}

*The generation (doubling) time was calculated from the slope of the steepest section of the growth curves obtained during $6 \mathrm{~h}$ that gave a correlation coefficient of $>0.98$ (see Fig. 1). 


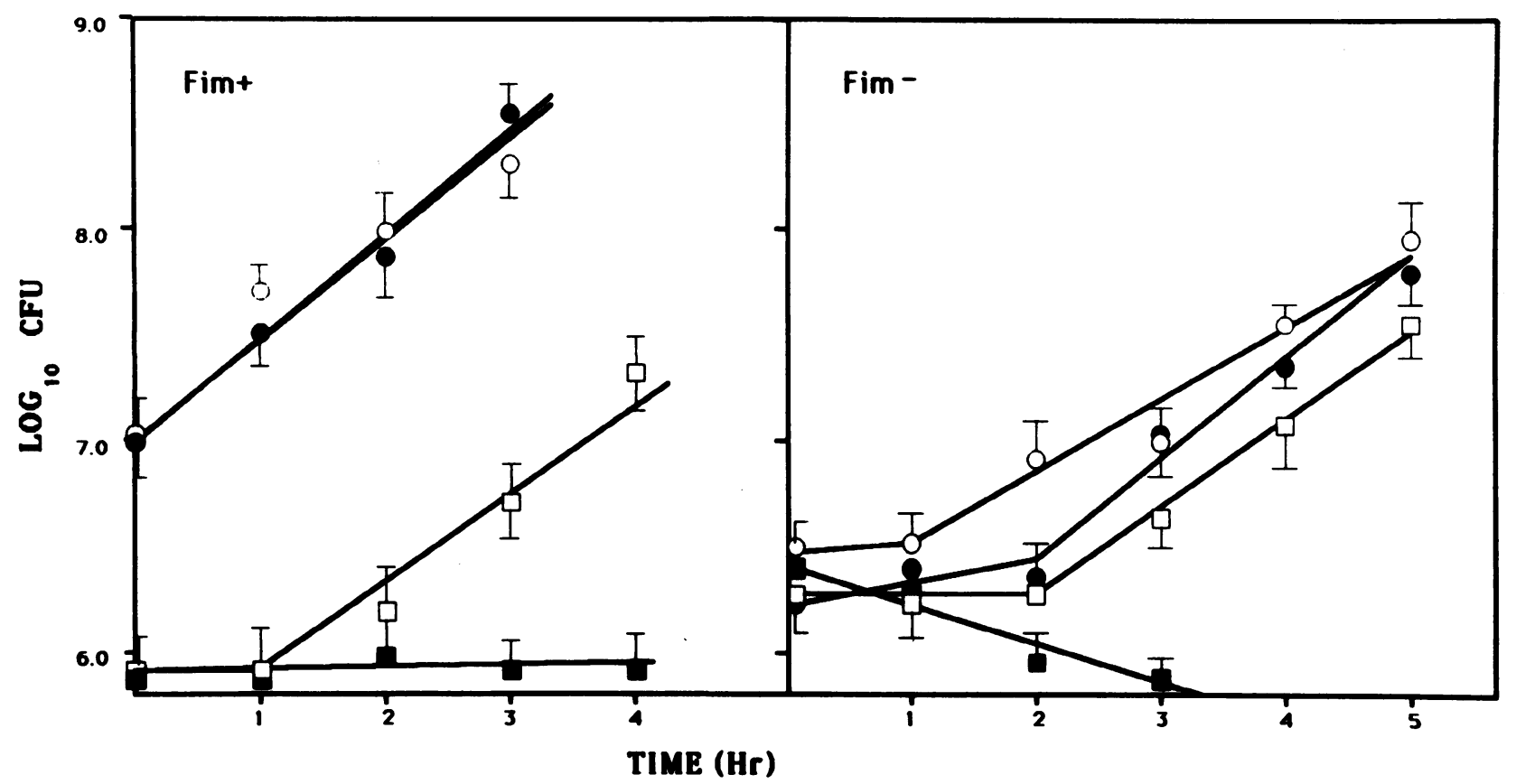

Figure 1. Effects of CCL6 tissue culture cells on growth of Fim ${ }^{+}$(CHS50) and Fim ${ }^{-}$(VL584) strains of E. coli. Determination of bacterial growth was done in wells containing $3 \mathrm{ml}$ of Hanks' MEM without (squares) or with (circles) tissue culture cell monolayer that were either supplemented (open symbols) or unsupplemented (solid symbols) with $10 \mu \mathrm{g} / \mathrm{ml} \mathrm{proline.}$

between the Fim $^{-}$and Fim ${ }^{+}$variants in wells devoid of tissue cells but containing medium supplemented with proline (Table I). We did not see this difference, however, when the organisms were grown in wells containing proline and $\alpha$-methyl-D-mannoside $(20 \mu \mathrm{g} / \mathrm{ml})$, or in glass tubes containing proline. Thus, in the absence of tissue cells the different length of lag phase (i.e., $56.5 \mathrm{vs} .125 \mathrm{~min}$ ) probably reflects the effect of mannose-sensitive interaction between the plastic wells and the fimbriate bacteria.

In another set of experiments, the $\mathrm{Fim}^{+}$and $\mathrm{Fim}^{-}$strains were grown in wells containing tissue cells and enough $\alpha$-methylD-mannoside $(20 \mu \mathrm{g} / \mathrm{ml})$ to prevent attachment of $\mathrm{Fim}^{+}$bacteria to the tissue cells. The duration of the lag phase for the Fim ${ }^{+}$ and $\mathrm{Fim}^{-}$strains under these conditions was identical, $1 \mathrm{~h}$ in proline- $(10 \mu \mathrm{g} / \mathrm{ml})$ supplemented medium and $2 \mathrm{~h}$ in unsupplemented medium, suggesting that the two isogenic strains differ only in fimbriation. Thus, any growth advantage of the $\mathrm{Fim}^{+}$ variant is due solely to its enhanced ability to attach to the tissue cells.

To see whether the growth factor secreted by the tissue cells is mainly proline, we used two additional proline auxotrophic strains of E. coli (AB 2659 and Met F3455) and compared the growth of the bacteria in Hanks' MEM with that in tissue-conditioned medium. The growth of the proline auxotrophic strains in conditioned medium not supplemented with proline was equivalent to that of medium supplemented with $2 \mu \mathrm{g} / \mathrm{ml}$ proline (Table II). The amino acid analysis of fresh medium showed no detectable proline, whereas that of conditioned medium (i.e., supernatant incubated $5 \frac{1}{2} \mathrm{~h}$ in wells containing tissue culture cells) showed $1.6 \mu \mathrm{g} / \mathrm{ml}$ proline. The results suggest that proline is indeed one of the growth factors secreted by the tissue cells that is required by all three proline auxotroph strains.

When the $\mathrm{Fim}^{-}$organisms were cultured in the presence of both proline and tissue cells, the lag period was shorter than when grown in the presence of proline alone. To determine whether the tissue cells secrete growth factors other than proline, we performed similar experiments to those described in Table I with $\mathrm{Pro}^{+}$derivatives of the $\mathrm{Fim}^{+}$and $\mathrm{Fim}^{-}$isogenic variants (VL798 and VL799, respectively), instead of the parent Pro $^{-}$ strains. We found that the Fim ${ }^{-}$started to grow $1 \mathrm{~h}$ after inoculation while the Fim ${ }^{+}$strain started to grow immediately. The results suggest that tissue cells provide factors other than proline that promote growth.

Table II. Growth of Proline Auxotrophic Strains of E. coli in either Proline-supplemented or Conditioned Medium*

\begin{tabular}{llll}
\hline E. coli strain & $\begin{array}{l}\text { Conditioned } \\
\text { medium }\end{array}$ & Proline & OD $_{\text {s40 }}$ after $24 \mathrm{~h}$ \\
\hline & & $\mu \mathrm{g} / \mathrm{ml}$ & \\
CSH50 & - & 0 & 0 \\
& - & 1 & 0.02 \\
& - & 2 & 0.035 \\
& - & 4 & 0.07 \\
& - & 5 & 0.09 \\
AB2659 & - & 10 & 0.15 \\
MetF3455 & + & 0 & 0.03 \\
CSH50 & + & 0 & 0.029 \\
& + & 0 & 0.03 \\
\hline
\end{tabular}

*3 $\mathrm{ml}$ of conditioned medium derived from $5 \mathrm{~h}$ of incubation with tissue culture cells (CCL6) of Hanks' MEM, not supplemented with proline, were inoculated with the various Pro- strains. After $24 \mathrm{~h}$ at $37^{\circ} \mathrm{C}$ the total bacterial mass was determined spectrophotometrically. A representative growth under the same conditions of strain CSH50 in Hanks' MEM supplemented with various concentrations of proline is included. 
Table III. Distribution of cAMP Secreted by the Various E. coli K-12 Strains Grown with Intestinal Tissue Culture Cell Monolayer

\begin{tabular}{|c|c|c|c|}
\hline E. coli strain & Medium & $\begin{array}{l}\text { Tissue cell } \\
\text { monolayer }\end{array}$ & $\begin{array}{l}\text { CAMP associated } \\
\text { with tissue cell } \\
\text { monolayers }\end{array}$ \\
\hline & pmol cAMP/well* & pmol cAMP/well* & \% total \\
\hline CSH50 $\left(\right.$ Fim $\left.^{+}\right)$ & $190.0 \pm 29.5$ & $69.5 \pm 9.3$ & $26.8 \pm 2.64$ \\
\hline VL584 $\left(\right.$ Fim $\left.^{-}\right)$ & $104.5 \pm 31.0$ & $0.08 \pm 0.2$ & $0.8 \pm 0.19$ \\
\hline \multicolumn{4}{|l|}{ VL391 } \\
\hline$\left(\mathrm{Fim}^{+} \mathrm{Cya}^{-}\right)$ & $<1.0$ & $<1.0$ & \\
\hline Culture filtrate of & & & \\
\hline CSH50 $\left(\mathrm{Fim}^{+}\right)$ & $1070 \pm 50.0$ & $20.0 \pm 1.34$ & $1.8 \pm 0.1$ \\
\hline
\end{tabular}

*cAMP, associated with tissue culture cells and in IBMX-containing medium was determined after 6-h incubation with the indicated $E$. coli strains. The low, control values of cAMP (2-5 pmol cAMP/ well) associated with tissue culture cells not exposed to bacteria but treated under identical conditions were subtracted from experimental values obtained in the same experiment.

Diffusion of bacterial CAMP from the monolayer-medium interface. The above results suggest that $\mathrm{Fim}^{+} E$. coli bacteria have a growth advantage over the $\mathrm{Fim}^{-}$bacteria in wells containing intestinal tissue cell monolayer, possibly because of the increased proximity of the adherent bacteria to a high concentration of the nutrient source. To test the hypothesis that such proximity places these adherent bacteria in a region where the concentrations of the product(s) of bacterial and tissue culture cells is elevated, we next examined the diffusion characteristics of an easily measured small molecule diffusing from the monolayer-medium interface. We chose bacterial cAMP, because it is known that $E$. coli bacteria secrete most of the cAMP they produce during their growth (12).

Both $\mathrm{Fim}^{+}$and $\mathrm{Fim}^{-}$derivatives produced identical amounts of cAMP, which was predominantly secreted into the medium (Table III). As expected, the $\mathrm{Fim}^{+} \mathrm{Cya}^{-}$mutant produced negligible amounts of CAMP. When the organisms were allowed to grow under identical conditions but in wells containing tissue cell monolayers, $\sim 20-30 \%$ of the cAMP produced by the adherent $\left(\mathrm{Fim}^{+}\right)$bacteria remained associated with the tissue culture cells as compared with only $0.8 \%$ of that produced by the isogenic, nonadherent $\left(\mathrm{Fim}^{-}\right)$bacteria. No detectable cAMP was measured in wells exposed to the Fim ${ }^{-}$strain and washed free of nonadherent bacteria, which suggests that the negligible amount of nonspecific adherence of Fim $^{-}$bacteria did not produce detectable amounts of cAMP. To show that all of the CAMP was of bacterial origin, we repeated the experiments in the presence or absence of isobutyl-methylxanthine (IBMX), a specific inhibitor of cAMP phosphodiesterase activity in eukaryotic cells. We found no difference in cAMP levels between the treated and untreated cultures (data not shown). To demonstrate the efficiency of IBMX in this system, we added $40 \mu \mathrm{g} / \mathrm{ml}$ of cholera toxin to the medium (as an extrinsic stimulator of eukaryoctic adenylate cyclase) in the absence or presence of IBMX. We found that the addition of IBMX under these conditions increased tissue culture cell cAMP > 16-fold (from 5 to $80 \mathrm{pmol} /$ well). These results indicated that virtually all of the cAMP in the experiments described in Table III was of bacterial origin.

The above findings show that a significant fraction (up to $30 \%$ ) of the total cAMP secreted by the adherent $\left(\mathrm{Fim}^{+}\right)$bacteria remained associated with the tissue cell monolayer in wells where the culture medium was aspirated without further washings of the cell monolayer. In contrast, when monolayers were instead exposed to bacteria-free culture filtrates, which contained as much as 1070 pmol cAMP, we found that only $1.8 \%$ of this amount remained associated with the cell monolayer (Table III). When cell monolayers were washed vigorously with glucosecontaining medium (to repress new bacterial cAMP synthesis [13]), only $0.8 \%$ of the bacterial cAMP remained associated with the monolayer. In contrast, similar washing with glucose-free medium, which allows continued bacterial synthesis of cAMP (13), resulted in $25 \%$ of the total secreted cAMP associated with the monolayer. Thus the high concentration gradient of bacterial products at the monolayer interface required both adherent bacteria and continued bacterial synthesis.

$L T$ toxin activity of $E$. coli adherent to $Y 1$ mouse adrenal cells. The results described above suggest that the concentration of potentially toxic products, secreted by adherent bacteria, should be much higher in the vicinity of the tissue cells, as compared with that in the bulk of the medium. To test this hypothesis, we examined the biological activity of LT toxin secreted by bac-

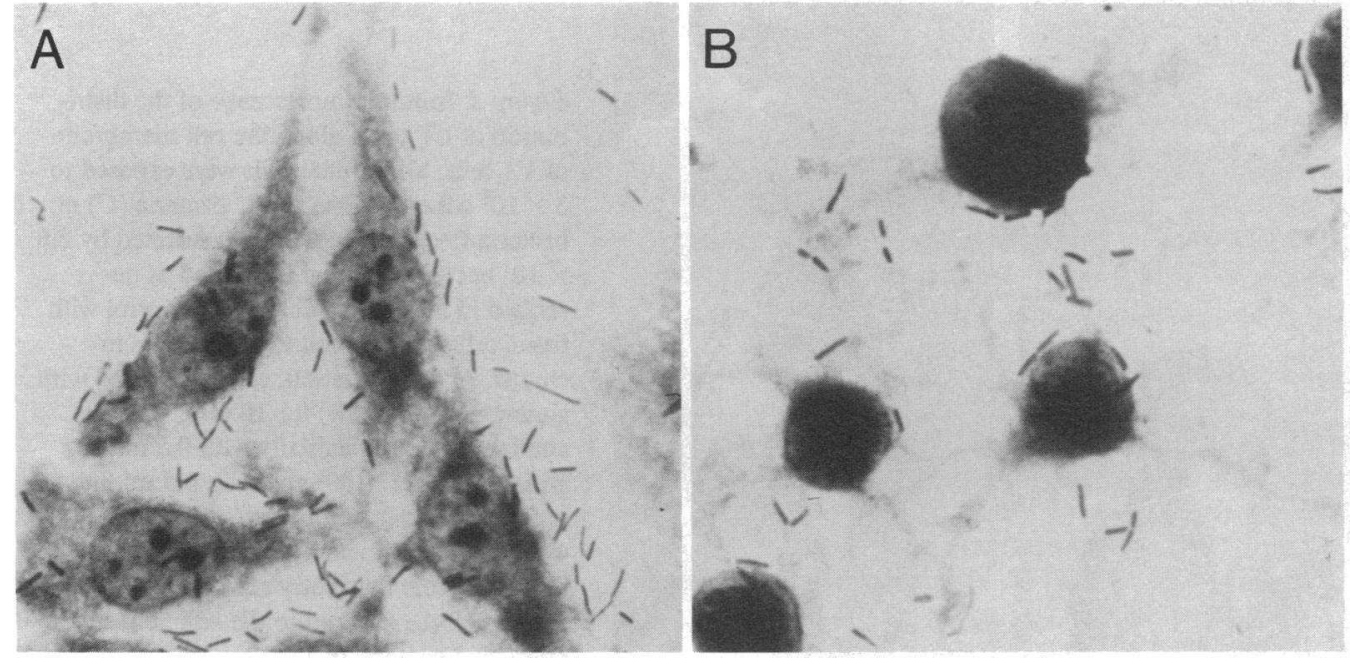

Figure 2. Rounding up of $\mathrm{Y} 1$ mouse adrenal cells by adherent $\mathrm{Fim}^{+} \mathrm{Tox}^{+}$derivative of E. coli strain CSH50. B, round $Y 1$ cells containing adherent Fim $^{+}$Tox $^{+}$bacteria (Table III). A, control of Fim $^{+}$Tox $^{-} E$. coli strain CSH50 adherent to Y1 cells (Table III). 
teria adherent to Y1 mouse adrenal cells, which round up upon exposure to the LT toxin (8). The LT secreted by the Fim ${ }^{+} \mathrm{Tox}^{+}$ bacterial suspension caused rounding up of Y1 cells in a dosedependent fashion (Table IV) with no detectable LT toxic activity in the supernatant of a suspension containing $6 \times 10^{6}$ bacteria. When Fim $^{+}$Tox $^{+}$bacteria were allowed to adhere before assay, however, as few as $2.6 \times 10^{5}$ bacteria adherent per monolayer caused $\sim 20 \%$ rounding up of cells (Table IV). No detectable LT toxin activity was observed in conditioned medium derived from tissue cells containing as many as $1.6 \times 10^{6}$ adherent bacteria per well. Although there is some loss of LT toxin activity during transfer and incubation of conditioned medium (Table IV), this loss of activity cannot account for the lack of any detectable rounding up of cells in any of the conditioned media derived from tissue cells monolayers containing adherent Fim ${ }^{+}$ $\mathrm{Tox}^{+}$bacteria. There was no detectable toxic activity in wells containing Fim ${ }^{+}$Tox $^{-}$bacteria (Table IV; Fig. 2), indicating that the rounding up of $\mathrm{Y} 1$ cells containing adherent $\mathrm{Fim}^{+} \mathrm{Tox}^{+}$ bacteria is due to LT toxin. Tissue cells were exposed to various amounts of Fim $^{-} \mathrm{Tox}^{+}$bacteria under similar experimental conditions. The number of nonadherent bacteria per well needed to be present to cause $20 \%$ rounding up of cells was as high as $1 \times 10^{7}$ (data not shown). When the nonadherent bacteria of the Fim ${ }^{-} \mathrm{Tox}^{+}$strain were removed by washing and wells were further incubated, no LT toxic activity was detected, indicating that the negligible amount of nonspecific adherence was insufficient to cause any rounding up of tissue cells.

The distribution of LT toxin bound by tissue cells along the cell membrane was examined by indirect immunofluorescence. We noticed a homogeneous distribution along the cell membrane of $Y 1$ cells exposed to soluble LT toxin, in contrast to a spotty distribution on cells exposed to adherent $\mathrm{Fim}^{+} \mathrm{Tox}^{+}$bacteria (Fig. 3), suggesting that only part of the cell membrane was exposed to the toxin.

\section{Discussion}

The aim of the present study was to examine two important physiological events subsequent to bacterial adherence to animal cells. We measured the availability of bacterial nutrients secreted by tissue cells and the distribution of bacteria secretion products during growth of a fimbriate, proline-auxotrophic strain of $E$. coli. The results suggest that tissue cell cultures provide a proline substitute(s) that supports bacterial growth. The adherent (Fim ${ }^{+}$) bacteria benefit more from such growth factors than nonadherent (Fim ${ }^{-}$) bacteria, as shown by the absence of a lag phase before initiation of growth of the former. Because the growth of proline auxotrophic $E$. coli is dependent on a critical concentration of proline, it would appear that the concentrations of amino acids (and possibly other growth factors) in the space proximal to the monolayer is much higher than in the bulk of the medium. This concentration gradient could account for the early initiation of growth of the adherent bacteria and is reminiscent of food scavanging yielding a selective growth advantage of adherent marine bacteria (14).

Likewise, when concentration gradients of bacterial products were examined, about a third of the total amount of cAMP produced by the growing adherent bacteria remained associated with the tissue cell monolayer, while virtually all of the nucleotide secreted by nonadherent bacteria diffused into the medium. The fraction of cAMP that remained associated with the intestinal cell monolayer was produced by the adherent bacteria and not by the tissue cells because: $(a)$ no cAMP could be detected in the medium by growing a $\mathrm{Fim}^{+} \mathrm{Cya}^{-}$derivative adherent to tissue cells, suggesting that the adherence of bacteria to the tissue cells alone does not trigger the latter to produce cAMP; $(b)$ the cell-associated cAMP is readily washed by vigorous washing only with solutions that induce catabolite repression of cAMP synthesis by the bacteria; and (c) IBMX, a cAMP phosphodiesterase inhibitor, which we have shown to be capable of affecting cAMP levels of tissue-cell, but not of bacterial origin, had no effect on cAMP levels during the test. Thus, the increase in cell-associated cAMP was not the result of stimulated tissue cell production. The association of cAMP synthesized by $\mathrm{Fim}^{+}$bacteria with the cell monolayer is not the result of unique binding properties of this molecule, because only $1.8 \%$ of exogenously added cAMP remained associated with the cell monolayer and because adherent bacteria were unable to maintain the concentration gradient when CAMP production was slowed by adding glucose.

Unlike the small molecule cAMP, which is readily secreted
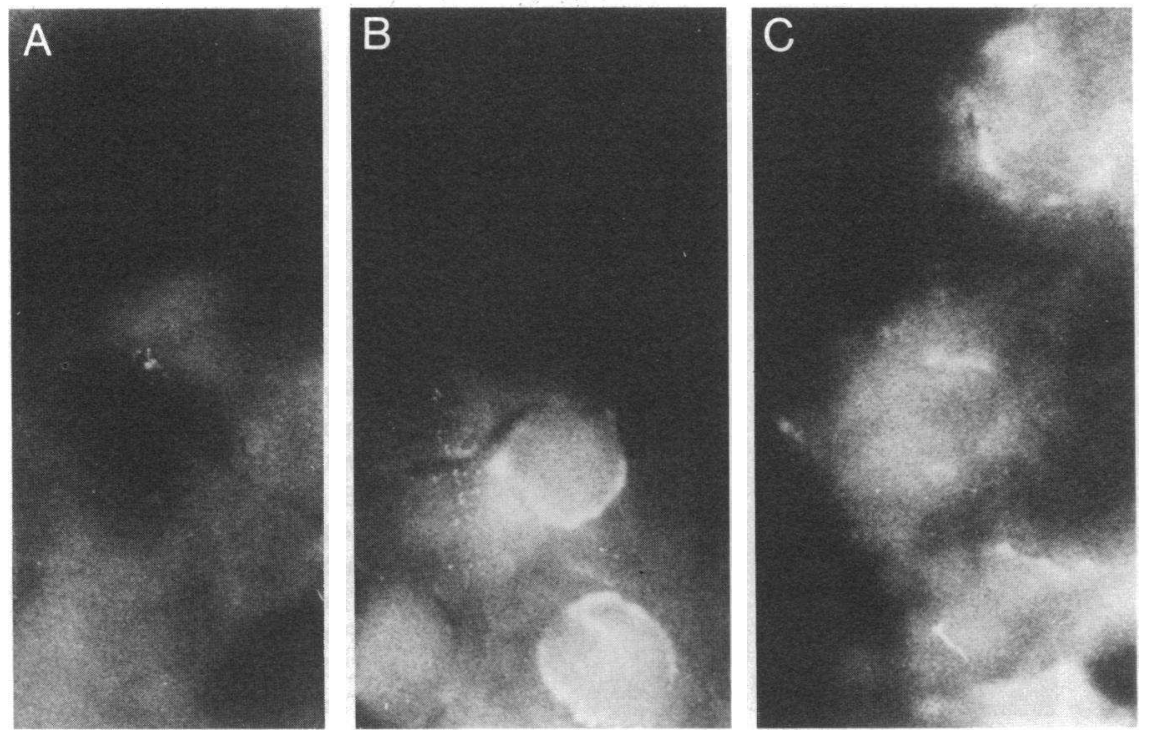

Figure 3. Immunofluorescence of the distribution of LT toxin along the cell membrane of $Y 1$ cells. $Y 1$ adrenal cells were exposed to $3 \times 10^{5}$ adherent Fim $^{+}$Tox $^{+}$bacteria $(C)$ or bacteria-free, soluble LT toxin secreted by 2.6 $\times 10^{7}$ bacteria $(B)$, and incubated as described in legend to Table III. A control with tissue cells not exposed to toxin $(A)$ is in cluded. After incubation, cells were fixed with glutaraldehyde $(0.5 \%)$ for $10 \mathrm{~min}$, washed, and incubated sequentially with $0.5 \mathrm{ml}$ of anti-LT toxin (1:100) and with $0.5 \mathrm{ml}$ fluorescein-labeled goat anti-rabbit immunoglobulin (1:20) (Kallestad Laboratories, Inc., Austin, TX). Note the spotty staining of toxin on the tissue cells exposed to the adherent, toxinproducing bacteria $(C)$. 
by $E$. coli cells, and in contrast to the efficient secretion of cholera toxin in Vibrio cholerae, the analogous enterotoxin form $E$. coli, LT, is primarily cell associated (15). Nevertheless, small amounts of LT can be detected in supernatant fractions of growing $E$. coli cells (15). (Most of this extracellular LT is actually associated with membrane vesicles, which are steadily released from sections of newly synthesized outer membrane during $E$. coli growth [16]. Thus, although we are using the term secreted LT to denote conceptually the LT that is released by the cells, the process of LT secretion is complex.) Because $E$. coli is so inefficient at secreting LT, the small amount of enterotoxin liberated from the cells might need to be released, whether as free toxin or vesicle-packaged toxin, at an optimal site (i.e., adjacent to the target receptors) to cause toxic effects. The results described in Table IV indicate that the small amount of LT secreted by $E$. coli adherent to Y1 mouse adrenal cells is about 100 times more concentrated in the space proximal to the cells than in the bulk of the medium. This is most probably the reason for the toxic activity detected in wells containing the Y1 cells and adherent $\mathrm{Fim}^{+} \mathrm{Tox}^{+} E$. coli, but not in the conditioned medium derived from these wells. These results are in agreement with

Table IV. Effect of LT Toxin Secreted by E. coli Adherent to Y1 Mouse Adrenal Cells*

\begin{tabular}{|c|c|c|c|c|}
\hline \multirow{2}{*}{$\begin{array}{l}\begin{array}{l}\text { Origin of } \\
\text { LT toxin }\end{array} \\
\text { Supernatant of } \\
\text { Fim }^{+} \text {Tox }^{+} \\
\text {suspension }\end{array}$} & \multirow{3}{*}{$\begin{array}{l}\begin{array}{l}\text { Number of } \\
\text { bacteria }\end{array} \\
8.1 \times 10^{8}\end{array}$} & \multicolumn{3}{|c|}{ Percent rounding cells exposed to } \\
\hline & & Supernatant & $\begin{array}{l}\text { Conditioned } \\
\text { medium }\end{array}$ & $\begin{array}{r}\text { Supernatant } \\
+ \text { anti-LT }\end{array}$ \\
\hline & & $>90$ & $>90$ & $\mathbf{N D}^{\dagger}$ \\
\hline & $1.0 \times 10^{8}$ & $>90$ & $70 \pm 10$ & $20 \pm 5$ \\
\hline & $5.0 \times 10^{7}$ & $70 \pm 10$ & $50 \pm 10$ & $10 \pm 5$ \\
\hline & $2.6 \times 10^{7}$ & $50 \pm 10$ & $20 \pm 5$ & $5 \pm 2$ \\
\hline & $6.0 \times 10^{6}$ & $<5$ & ND & ND \\
\hline \multirow[t]{5}{*}{$\begin{array}{l}\text { Adherent } \\
\text { bacteria }\end{array}$} & & $\operatorname{Fim}^{+} \operatorname{Tox}^{+}$ & $\begin{array}{l}\text { Conditioned } \\
\text { medium }\end{array}$ & Fim $^{+}$Tox $^{-}$ \\
\hline & $1.6 \times 10^{6}$ & $>90$ & $<5$ & $<5$ \\
\hline & $5.0 \times 10^{5}$ & $75 \pm 10$ & $<5$ & $<5$ \\
\hline & $3.0 \times 10^{5}$ & $55 \pm 10$ & $<5$ & $<5$ \\
\hline & $2.6 \times 10^{5}$ & $20 \pm 5$ & $<5$ & $<5$ \\
\hline
\end{tabular}

To obtain monolayers with various amounts of indicated adherent bacteria before assay of LT toxin activity, the $\mathrm{Y} 1$ cell monolayers were preexposed to the bacterial suspensions containing various amounts of bacteria and constant amount of anti-LT toxin (1:200) to neutralize any presecreted toxin. After incubation at $37^{\circ} \mathrm{C}$ for $30 \mathrm{~min}$, the monolayers were washed free of nonadherent bacteria and anti-LT toxin, followed by adding fresh medium. After $4 \mathrm{~h}$ incubation, the percent rounding up of cells was determined and the medium designated conditioned medium was transferred to fresh monolayers to determine $\mathrm{LT}$ toxin activity after $4 \mathrm{~h}$ incubation at $37^{\circ} \mathrm{C}$. The number of adherent bacteria per well was determined microscopically on stained monolayers.

*Wells containing tissue monolayers of $\mathrm{Y} 1$ cells were exposed to the supernatants derived from bacterial suspensions containing various amounts of indicated bacteria. The percent of rounded cells was determined after $4 \mathrm{~h}$ incubation at $37^{\circ} \mathrm{C}$ and the medium designated and conditioned medium was transferred to fresh monolayer to determine LT toxin activity after $4 \mathrm{~h}$ incubation at $37^{\circ} \mathrm{C}$.

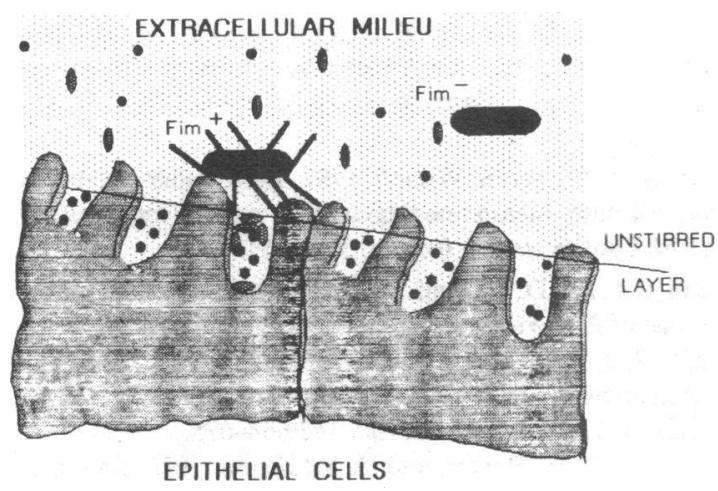

Figure 4. Schematic distribution of products secreted by epithelial cells ( filled circle) and by bacteria (shaded oval) adherent to the cells, between the proximal and the distal milieu of the epithelial cell surfaces. The secretory products accumulate in pockets of the unstirred layer formed by the ruffle structure of the epithelial cell membrane and the lid of the adherent bacterium.

the distribution of cAMP secreted by adherent bacteria. Prior workers have suggested that the role of bacterial adhesive factors in promoting enterotoxigenic $E$. coli diarrhea is primarily to permit bacterial multiplication and persistence in the bowel (17). Our findings here directly support the conjecture of Witholt and co-workers $(3,16)$ that the additional effect provided by bacterial adherence factors of enhanced toxin delivery may also be important in the production of clinical disease.

We interpret our results by postulating that certain products secreted by either the tissue cells or the cell-adherent $E$. coli accumulate in crypts formed by the ruffle structures of the animal cells and the lids formed by the adherent bacteria. This trapped or unstirred layer limits the diffusion of such products (including vesicle-packaged toxin) to the surrounding medium, as Fig. 4 depicts. This hypothesis may explain both the nonhomogeneous distribution of CAMP secreted by growing and adherent $E$. coli bacteria, the enhanced toxic activity caused by LT-secreting adherent bacteria, the spotty distribution of LT toxin along the cell membrane of $\mathrm{Y} 1$ cells exposed to $\mathrm{Fim}^{+} \mathrm{Tox}^{+}$bacteria, and the growth advantage of the adherent bacteria resulting from the proximity of the organisms to relatively high concentrations of nutrients accumulated in such crypts (Fig. 4). This model is also compatible with the concept of an unstirred layer found to occur in intestinal tissue cells (18). It is, therefore, conceivable that growth-limiting factors secreted by the host cells and toxic products secreted by the bacteria in vivo in an open system would reach effective concentrations in the case of adherent but not in the case of nonadherent bacteria, thereby increasing the pathogenicity of the adhering phenotype.

\section{Acknowledgments}

We acknowledge the editorial comments of Cary Engleberg.

This work was supported in part by Public Health Service Research Grant No. AI-19670, a Research Career Development Award (to Dr. Eisenstein), all from the National Institutes of Health, and by a Basic Science Research Grant of Tel-Aviv University.

\section{References}

1. Beachey, E. H., B. I. Eisenstein, and I. Ofek. 1982. Current Concepts: Bacterial Adherence in Infectious Diseases. Scope Monograph. Kalamazoo, MI. 1-52. 
2. Ofek, I., and E. H. Beachey. 1980. General concepts and principles of bacterial adherence. In Bacterial Adherence: Receptors and Recognition. E. H. Beachey, editor. Series B, Vol. 6. London, Chapman and Hall, 1-29.

3. Middeldorp, J. M., and B. Witholt. 1981. K-88 mediated binding of Escherichia coli outer membrane fragments to procine intestinal epithelial cell brush borders. Infect. Immun. 31:42-51.

4. Eisenstein, B. I., and D. C. Dodd. 1982. Pseudocatabolite repression of type 1 fimbriae of Escherichia coli. J. Bacteriol. 151:1560-1567.

5. Freitag, C. S., J. M. Abraham, J. R. Clements, and B. I. Eisenstein. 1985. Genetic analysis of phase variation control of expression of type 1 fimbriae of Escherichia coli. J. Bacteriol. 162:668-675.

6. Steiner, A. L., S. W. Porker, and D. M. Kipnis. 1972. Radioimmunoassay for cyclic nucleotides. J. Biol. Chem. 247:1106-1113.

7. Harper, J. E., and O. Brooker. 1975. Femtomole sensitive radioimmunoassay for cyclic AMP and cyclic GMP after 2'O acetylation by acetic anhydride in aqueous solution. J. Cyclic Nucleotide Res. 1: 207-218.

8. Donta, S. T., H. W. Moon, and S. C. Whipp. 1974. Detection of heat-labile Escherichia coli enterotoxin with the use of adrenal cells in tissue culture. Science (Wash. DC). 183:334-336.

9. Perry, A., I. Ofek, and F. J. Silverblatt. 1983. Enhancement of mannose-mediated stimulation of human granulocytes by Type-1 fimbriae aggregated with antibodies on Escherichia coli surfaces. Infect. Immun. 39:1334-1345.

10. Clements, J. D., and R. A. Finkelstein. 1978. Demonstration of shared and unique immunological determinants in enterotoxins from Vibrio cholerae. Infect. Immun. 22:709-713.

11. Ofek, I., D. Mirelman, and N. Sharon. 1977. Adherence of Escherichia coli to human mucosal cells mediated by mannose receptors. Nature (Lond.). 265:623-625.

12. Pastan, I., and S. Adhya. 1976. Cyclic adenosine 5'-monophosphate in Escherichia coli. Bacteriol. Rev. 40:527-551.

13. Wayne, P. K., and O. M. Rosen. 1974. Cyclic 3'-5' adenosine monophosphate in Escherichia coli during transient and catabolite repression. Proc. Natl. Acad. Sci. USA. 71:1436-1440.

14. Pearl, H. W. 1985. Influence of attachment of microbial metabolism and growth in aquatic ecosystems. In Bacterial Adhesion: Mechanisms and Physiological Significance. D. C. Savage and M. Fletcher, editors. Plenum Publishing Corp., New York. 363-400.

15. Bramucci, M. G., E. M. Twiddy, W. B. Baine, and R. K. Holmes. 1981. Isolation and characterization of hypertoxinogenic $(h t x)$ mutants of Escherichia coli KL320(pCG86). Infect. Immun. 32:1034-1044.

16. Gankema, H., J. Wensink, P. A. M. Guinée, W. H. Jansen, and B. Witholt. 1980. Some characteristics of the outer membrane material released by growing enterotoxigenic Escherichia coli. Infect. Immun. 29: 704-713.

17. Satterwhite, T. K., D. G. Evans, H. L. Dupont, and D. J. Evans, Jr. 1978. Role of Escherichia coli colonization factor antigen in acute diarrhea. Lancet. ii:181-184.

18. Allen, A. 1984. Structure and function of gastrointestinal mucus in attachment of organisms to the gut mucosa. E. L. Boedecker, editor. CRC Press, Inc., Boca Raton, Florida. 3-11. 